\title{
ASCORBIC ACID CONCENTRATION AND PRETERM PREMATURE RUPTURE OF MEMBRANES (PPROM)
}

\section{Dr. Priti Singh* \\ Dr.Krishna Sinha}

Senior Resident, Dept. of Obs. and Gynae., JLN medical College, Bhagalpur $1^{*}$ Corresponding Author

Associate Professor, Dept. of Obs. and Gynae. , JLN medical College, Bhagalpur

ABSTRACT Pprom (preterm premature rupture of membranes )is one of the most common complication of pregnancy contributing to major fetal morbidity and mortality. So it is important to study causes like micronutrient deficiency which can lead to pprom so that it can be prevented and hence fetal complications can be reduced.Place of study: Department of Obstetrics \& Gynecology, Jawahar Lal Nehru Medical College and Hospital, Bhagalpur, Bihar.Duration of study: period of 1 year. Prospective randomised study.

\section{KEYWORDS : ASCORBIC ACID, PRETERM PREMATURE RUPTURE OF MEMBRANE, PPROM}

\section{INTRODUCTION}

Preterm premature rupture of membranes (PPROM) complicates $1-3 \%$ of all pregnancies and is the major contributory factor for perinatal morbidity and mortality. The cause of PPROM is unknown but the pathophysiology appears to be multifactorial. Recent evidence suggests that membrane rupture is also related to biochemical processes such as abnormalities in collagen structure and formation as well as increased oxidative stress. Micronutrient deficiency that leads to abnormal collagen structure has been associated with increased risk of PPROM.

The micronutrient vitamin $\mathrm{C}$ is an effective water soluble antioxidant that scavenges several reactive oxygen species, thus reducing oxidative stress. Ascorbic acid also causes downregulation of the metalloproteinase- 2 and biosynthesis of collagen where it is required for the formation of triple helical structure of collagen.Thus, ascorbic acid participates in the equilibrium between synthesis and degradation of collagen and this may be critical in reducing the occurrence of preterm PROM.

Daily supplementation of $100 \mathrm{mg} /$ day vitamin $\mathrm{C}$ after 20 weeks gestation effectively reduces the incidence of PROM.This study compares the serum vitamin $\mathrm{C}$ levels in women with preterm PROM and women without PPROM.

\section{AIMS AND OBJECTIVES}

Relation of maternal plasma vitamin $\mathrm{C}$ concentration in women with PPROM and women without PPROM and also to study the difference in maternal \& perinatal morbidity and mortality in both the groups.

\section{MATERIALS AND METHODS}

Prospective randomised study was conducted for a period of 1 year where 40 women with singleton pregnancies between 28 and 37 weeks were recruited

Study group: included 20 antenatal women with history of PPROM and fulfilled the inclusion and exclusion criteria.

Control group: also included 20 pregnant women without PPROM following every recorded case of PPROM and matched for gestational age Sterile per speculum examination along with nitrazine test and ferning test was carried out to confirm PPROM. Vaginal swab culture was obtained. After 6-8 h fasting, maternal $5 \mathrm{ml}$ venous blood samples were collected in EDTA vial to estimate vitamin C concentration from both the groups. Vitamin $\mathrm{C}$ cut off limit taken as $0.6 \mathrm{mg} / \mathrm{dl}$, and all the patients were followed till the delivery

\section{RESULT}

There were no significant difference in age and parity the groups. $55 \%$ versus $62 \%$ of women belonged to $20-25$ years of age in study and control groups, respectively $68 \%$ women in study group compared to $58 \%$ in control group were multigravidas Majority (30\%) of women reported within 6-12 h of rupture of membrane.

\begin{tabular}{|c|c|}
\hline Duration(Hrs) & Study group (n = 20) \\
\hline$<6$ & $1(5 \%)$ \\
\hline $6-12$ & $7(35 \%)$ \\
\hline $12-24$ & $6(30 \%)$ \\
\hline $24-48$ & $4(20 \%)$ \\
\hline$>48$ & $2(10 \%)$ \\
\hline
\end{tabular}

Ascorbic acid levels were low in women with PPROM.There was a statistically significant difference in vitamin $C$ levels in both the groups, and the mean was $0.44 \pm 0.1$ versus $0.88 \pm$ $0.23 \mathrm{mg} / \mathrm{dl}$ in controls.

Plasma vitamin C levels declines linearly as the pregnancy advances.

With the increase in the duration of PPROM , the level of vitamin $\mathrm{C}$ decreases. When duration of $\mathrm{PPROM}<48 \mathrm{hrs}$, mean level of serum vitamin $\mathrm{C}$ is 0.3 to $0.47 \mathrm{mg} / \mathrm{dl}$ and it is around $0.11 \mathrm{mg} / \mathrm{dl}$ with PPROM $>48 \mathrm{hrs}$.

There was a significant difference in the mode of deliveries, and $60 \%$ of women underwent LSCS in the study group VS 30 $\%$ in the control group.

Maternal morbidity was increased in the study group as 2 (10 $\%$ ) women had wound gaping and prolonged hospital stay. NICU stay beyond $24 \mathrm{~h}$ was $70 \%$ versus $25 \%$ in the study and control groups, respectively.

Early neonatal deaths were more in the study group 20\% probably due to prematurity and low birth weight

Maternal and fetal outcome in both the groups

\begin{tabular}{|c|c|c|}
\hline & Study group & Control group \\
\hline Mode of deliveries & & \\
\hline LSCS & $12(60 \%)$ & $6(30 \%)$ \\
\hline NVD & $8(40 \%)$ & $14(70 \%)$ \\
\hline $\begin{array}{c}\text { Comorbidity like } \\
\text { Wound gaping }\end{array}$ & $2(10 \%)$ & nil \\
\hline NICU admissions & $14(70 \%)$ & $5(25 \%)$ \\
\hline Early neonatal death & $4(20 \%)$ & $1(5 \%)$ \\
\hline
\end{tabular}


DISCUSSION

The defect in collagen metabolism is the prime cause of PPROM which decreases the stability of membranes leading to its rupture. So Vitamin C supplementation during pregnancy can prevent preterm PROM and its various complications. This may be necessary to develop health strategies aimed at improving outcome by predicting and preventing PPROM

Similar to our study Osakhuwuomwan JA et al [8] reported that plasma vitamin $\mathrm{C}$ decreases with increasing gestational age, and its levels were low in women with PPROM compared to the women without PPROM $0.53 \pm 0.05$ versus $0.58 \pm 0.05 \mathrm{mg} / \mathrm{dl}$. A decreasing trend of vitamin $\mathrm{C}$ was observed in this study as the pregnancy advanced similar to the study conducted by Sharma et al.

Barett BM et al. [9] conducted a study and concluded that PROM patients had lower ratios of ascorbic acid in amniotic fluid than controls and lower ratios of amniotic fluid to serum ascorbic acid ( $\backslash$ |0.0001). Our study also showed lower ascorbic acid concentration in PROM women compared to the controls.

Ansori et al and Awolelu CO et al. [11] concluded no significant difference in the study and the control groups, which is contradictory to our study.

Mehrangiz et al. [12] reported that vitamin c supplementation prevents early rise of serum estriol, and its levels were low in women without PROM as compared to women receiving placebo $(p=0.044)$.

\section{CONCLUSION}

Vitamin C levels were low in PPROM patients and its concentration declines as the pregnancy advances. There is association of ascorbic acid and PPROM. Consumption of vitamin $\mathrm{C}$ may decrease the probability of PROM and PPROM. Vitamin $\mathrm{c}$ is essential for pregnant woman. Hence Vitamin C supplementation should be made mandatory along with iron and calcium to antenatal women to avoid the preventable complications of PPROM.

\section{REFERENCES:}

1. Mercer BM. Preterm premature rupture of the membranes: diagnosis and management. Clin Perinatol. 2004;31:765-82. doi: 10.1016/j.clp.2004.06.004. PubMed PMID: 15519427. [PubMed] [Google Scholar]

2. Ladfors L, Mattsson LA, Eriksson M, Milsom I. Prevalence and risk factors for prelabor rupture of the membranes (PROM) at or near-term in an urban Swedish population. J Perinat Med. 2000;28:491-6. doi: 10.1515/JPM.2000.066. PubMed PMID: 11155436. [PubMed] [Google Scholar]

3. Pasquier JC, Bujold E. A systematic review of intentional delivery in women with preterm prelabor rupture of membranes. J Matern Fetal Neonatal Med. 2007;20:567-8. doi: 10.1080/14767050701412651. PubMed PMID: 17674273. [PubMed] [Google Scholar]

4. ACOG Committee on Practice Bulletins-Obstetrics. ACOG Practice Bulletin No. 80: premature rupture of membranes. Clinical management guidelines for obstetrician-gynecologists. Obstet Gynecol. 2007;109:1007-19. PubMed PMID: 17400872. [PubMed] [Google Scholar]

5. Fortunato SJ, Menon R. Distinct molecular events suggest different pathways for preterm labor and premature rupture of membranes. Am J Obstet Gynecol. 2001;184:1399-405. doi: 10.1067/mob.2001.115122. PubMed PMID: 11408859. [PubMed] [Google Scholar]

6. Woods JR Jr. Reactive oxygen species and preterm premature rupture of membranes-a review. Placenta. 2001;22:S38-44. doi: 10.1053/plac.2001.0638. PubMed PMID: 11312627. [PubMed] [Google Scholar]

7. Levine M, Wang Y, Padayatty SJ, Morrow J. A new recommended dietary allowance of vitamin C for healthy young women. Proc Natl Acad Sci U S A. 2001;98:9842-6. doi: 10.1073/pnas.171318198. PubMed PMID: 11504949; PubMed Central PMCID: PMC55540. [PMC free article] [PubMed] [Google Scholar]

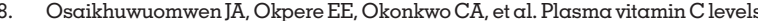
and risk of preterm prelabour rupture of membrane. Arch Gynecol Obstet. 2011;284(4):595.

9. Barett BM, Sowell A, Gunter E, et al. Potential role of ascorbic acid and beta carotene in the prevention of PROM. Int J Vitam Nutr Res. 1994;64(3):192-7.

10. Awoyelu CO, Agharanya JC, Oguntibeju OO. Ascorbic acid status in third trimester of pregnancy at delivery and in cord blood. Indian J Clin Biochem. 2004;19(1):54-6.

11. Zamani M, Goodarzi MT, Lavasani NS, et al. Effects of ascorbic Acid on serum level of unconjugated estriol and its relationship with preterm premature rupture of membrane: a double-blind randomized controlled clinical trial. Iran J Med Sci. 2013;38(3)

12. Tejero E, Perichart O, Pfeffer F, Casanueva E, Vadillo-Ortega F. Collagen synthesis during pregnancy, vitamin $\mathrm{C}$ availability, and risk of premature rupture of fetal membranes. Int J Gynaecol Obstet. 2003;81:29-34. doi 10.1016/S0020-7292(02)00400-9. PubMed PMID: 12676390. [PubMed] [Google Scholar]

13. Rumbold AR, Crowther CA, Haslam RR, Dekker GA, Robinson JS. ACTS Study Group Vitamins $\mathrm{C}$ and $\mathrm{E}$ and the risks of preeclampsia and perinatal complications. N Engl J Med. 2006;354:1796-806. doi: 10.1056/NEJMoa054186. PubMed PMID: 16641396. [PubMed] [Google Scholar]

14. Hedriana HL, Munro CJ, Eby-Wilkens EM, Lasley BL. Changes in rates of salivary estriol increases before parturition at term. Am J Obstet Gynecol. 2001;184:123-30. doi: 10.1067/mob.2001.108338. PubMed PMID: 11174491. [PubMed] [Google Scholar]

15. Ramsey PS, Andrews WW. Biochemical predictors of preterm labor: fetal fibronectin and salivary estriol. Clin Perinatol. 2003;30:701-33. doi: 10.1016/S0095-5108(03)00109-X. PubMed PMID: 14714920. [PubMed] [Google Scholar]

16. Plessinger MA, Woods JR Jr, Miller RK. Pretreatment of human amnion-chorion with vitamins $\mathrm{C}$ and $\mathrm{E}$ prevents hypochlorous acid-induced damage. Am J Obstet Gynecol. 2000;183:979-85. doi: 10.1067/mob.2000.106676. PubMed PMID: 11035350. [PubMed] [Google Scholar]

17. Siega-Riz AM, Promislow JH, Savitz DA, Thorp JM Jr, McDonald T. Vitamin C intake and the risk of preterm delivery. Am J Obstet Gynecol. 2003;189:519-25. doi: 10.1067/S0002-9378(03)00363-6. PubMed PMID: 14520228. [PubMed] [Google Scholar]

18. Spinnato JA 2nd, Freire S, Pinto e Silva JL, Rudge MV, Martins-Costa S, Koch $\mathrm{MA}$, et al. Antioxidant supplementation and premature rupture of the membranes: a planned secondary analysis. Am J Obstet Gynecol. 2008;199:el-8. doi: 10.1016/j.ajog.2008.07.011. PubMed PMID: 18928997; PubMed Central PMCID: PMC2723730. [PMC free article] [PubMed] [Google Scholar] 